\title{
PENGARUH CUSTOMER PERCEIVED VALUE, SERVICE QUALITY, DAN PHYSICAL ENVIRONMENT TERHADAP KEPUASAN DAN KESETIAAN PELANGGAN
}

\author{
Shelly Agustina Natawijaya \\ Program Studi Magister Manajemen Universitas Tarumanagara \\ shelly.agustina.natawijaya@gmail.com \\ Keni \\ Program Studi Magister Manajemen Universitas Tarumanegara
}

\begin{abstract}
The aim of this study are : First, to explore the effect of customer perceived value, service quality, and physical environment on customer loyalty. Second, to explore the effect of customer perceived value, service quality, and physical environment on customer satisfaction. Third, to explore the effect of customer satisfaction towards customer loyalty. Fourth, to find out if customer satisfaction can mediate customer perceived value, service quality, and physical environment towards customer loyalty. The method of data collection is purposive sampling. The samples of this research are collected from 326 respondents, who are the customers of furniture store in Jakarta. The technique of data analysis used in this study was regression analysis and mediating test to find put the hypotheses. The results are : (a) the relationship between customer perceived value, service quality, and physical environment have a significant and positive impact toward customer loyalty; (b) the relationship between customer perceived value, service quality, and physical environment have a significant and positive impact toward customer satisfaction; (c) customer satisfaction has a positive impact on customer loyalty; (d) customer satisfaction will mediate the effect of customer perceived value, service quality, and physical environment towards customer loyalty.
\end{abstract}

Keywords :customer perceived value, service quality, physical environment, customer satisfaction, customer loyalty

\section{PENDAHULUAN}

Dalam beberapa tahun terakhir, jumlah masyarakat kelas menengah di Indonesia terus meningkat yang menjadi sumber potensi bagi pebisnis. Seiring dengan pertumbuhan jumlah penduduk kelas menengah, permintaan terhadap properti turut meningkat.Perkembangan tersebut, membuat permintaan furniture di Indonesia pun turut mengalami peningkata .Pelanggan menjadi target utama keberhasilan bisnis karena pelanggan menjadi sumber pendapatan perusahaan. Maka dari itu, kesetiaan pelanggan adalah hal penting untuk diperhatikan. Menurut Tjiptono (2005), Loyalitas konsumen adalah situasi ideal yang paling diharapkan, dimana konsumen bersifat positif terhadap produk / produsen dan disertai pola pembelian ulang yang konsisten. Dengan memiliki pelanggan loyal, dapat menjadi aset yang bernilai bagi perusahaan.

Kesetiaan pelanggan dipengaruhi oleh customer perceived value dan service quality . Sejalan dengan Rasheed dan Abadi (2014), menjelaskan customer perceived valuedan service quality memiliki hubungan signifikan terhadap customer loyalty. Menurut Kotler dan Keller (2012:147) customer perceived value adalah : " the difference between the prospective customer's evaluation of all benefits and all the costs of an offering and the perceived alternatives." Menurut Parasuraman et al. (1996) menjelaskan bahwa service quality sebagai 
faktor penentu keberhasilan bagi perusahaan untuk membangun keunggulan kompetitif. Lebih lanjut, Sidharta dan Keni (2015) menyatakan bahwa physical environment memiliki hubungan yang positif terhadap customer loyalty. Menurut Yang dan Peterson (2004), kepuasan pelanggan merupakan komponen yang sangat menentukan bagi loyalitas pelanggan.

Tujuan dari penelitian ini adalah untuk mengetahui: (1) pengaruh a) customer perceived value, b) service quality, c) physical environment terhadap kesetiaan pelanggan; (2) pengaruh customer perceived value, b) service quality, c) physical environment terhadap kepuasan pelanggan; (3) pengaruh kepuasan pelanggan terhadap kesetiaan pelanggan; (4) apakah customer satisfaction dapat menjadi mediasi pengaruh a) customer perceived value, b) service quality, c) physical environment terhadap kesetiaan pelanggan. Hasil penelitian ini diharapkan dapat memberikan memberikan informasi kepada toko furniture dalam pengambilan keputusan untuk mempertahankan kesetiaan pelanggan dengan penggunaan faktor customer perceived value, service quality, physical environment dan kepuasan pelanggan.

\section{LANDASAN TEORI}

Definisi customer perceived value menurut Kotler (2012: 147) adalah: "the difference between the perspective customer's evaluation of all benefits and all the costs ofan offering and the perceived alternatives." Peneliti menyimpulkan customer perceived value adalah ekspektasi konsumen dengan membandingkan apakah yang dikeluarkan oleh pelanggan tersebut sesuai atau tidak dengan barang / jasa yang didapat.

Menurut Palmer (2011:287) " service quality is a highly abstract construct, in contrast to goods where technical aspect of quality predominate." Bisa dikatakan, service quality adalah segala cara untuk memenuhi harapan konsumen. Pelayanan dalam hal ini diartikan sebagai jasa berupa kecepatan, hubungan, kemampuan yang ditujukan melalui sikap dalam memberikan pelayanan.

Kemudian menurut Nguyen dan LeBlanc (2002:246) "physical environment is considered as the packaging of service and another contact element which may have strong impact on the customer satisfaction and his/her perception of the service quality". Jadi, physical environment adalah cara menampilkan produk yang ditawarkan oleh sebuah toko yang dapat menghadirkankenyamanan bagi para pengunjungnya.

Menurut Kotler dan Keller (2015:128) "satisfaction is a person's feeling of pleasure or disappointment that result from comparing product's perceived performance to their expectation.". Peneliti berpendapat bahwa kepuasan pelanggan adalah suatu evaluasi konsumen setelah pembelian terhadap suatu barang atau jasa yang dirasakannya (kinerja produk) dibandingkan dengan harapan konsumen.Untuk variabel kesetiaan pelanggan, menurut Griffin (2003:16), "customer loyalty is a non random purchase expressed over time by some decision making unit." Masih menurut Griffin (2003), kesetiaan pelanggan lebih banyak dikaitkan dengan perilaku (behavior) dari pada dengan sikap.Disni bisa dilihat, pelanggan yang setia adalah pelanggan yang memiliki komitmen mendalam terhadap produk atau jasa tersebut.

Pengaruh Customer Perceived Value, Service Quality, Physical Environment terhadap Kesetiaan Pelanggan. Menurut penelitian Rasheed dan Abadi (2004) menemukan bahwa customer perceived value dan service quality merupakan variabel penting dalam meningkatkan kesetiaan pelanggan. Dalam penelitiannya, Sidharta dan Keni (2015) physical environment mempunyai pengaruh yang positif terhadap customer loyalty. Berdasarkan paparan diatas, maka hipotesis penelitian adalah sebagai berikut :

$\mathrm{H} 1 \mathrm{a}$ :Terdapat pengaruh positif customer perceived value terhadap kesetiaan pelanggan. H1b: Terdapat pengaruh positif service quality terhadap kesetiaan pelanggan. 
H1c : Terdapat pengaruh positif physical environment terhadap kesetiaan pelanggan.

Pengaruh Customer Perceived Value, Service Quality, Physical Environment terhadap Kepuasan Pelanggan. Menurut penelitian yang dilakukan oleh McDougall dan Levesque (2000) menemukan bahwa customer perceived value dan service quality adalah alat terpenting / faktor terpenting untuk mencapai kepuasan pelanggan. Lebih lanjut, menurut Ryu et.al (2012) juga menyimpulkan bahwa kualitas physical environment berpengaruh signifikan terhadap kepuasan pelanggan. Berdasarkan paparan diatas, maka hipotesis penelitian adalah sebagai berikut :

$\mathrm{H} 2 \mathrm{a}$ :Terdapat pengaruh positif customer perceived value terhadap kepuasan pelanggan.

$\mathrm{H} 2 \mathrm{~b}$ : Terdapat pengaruh positif service quality terhadap kepuasan pelanggan.

$\mathrm{H} 2 \mathrm{c}$ : Terdapat pengaruh positif physical environment terhadap kepuasan pelanggan.

Pengaruh Kepuasan Pelanggan terhadap Kesetiaan Pelanggan. Penelitian yang dilakukan Yang dan Peterson (2004) menemukan bahwa kepuasan pelanggan memiliki hubungan positif terhadap kesetiaan pelanggan. Penelitian oleh Kandampully dan Suhartanto (2000) juga menemukan bahwa kepuasan pelanggan berpengaruh positif terhadap kesetiaan pelanggan. Berdasarkan paparan diatas, maka hipotesis penelitian adalah sebagai berikut :

H3 : Terdapat pengaruh positif antara pelanggan terhadap kesetiaan pelanggan.

Kepuasan Pelanggan Memediasi Customer Perceived Value, Service Quality, Physical Environment terhadap Kesetiaan Pelanggan. Dalam penelitiannya,Lai, Griffin dan Banin (2009) menyatakan bahwa perceived value memiliki pengaruh positif terhadap kesetiaan pelanggan dengan kepuasan pelanggan sebagai variabel mediasi. Penelitian yang dilakukan oleh Kaura,et.al (2015) menyimpulkan variabel service quality memiliki pengaruh positif terhadap kepuasan dan kesetiaan pelanggan. Dalam penelitian ini berhasil membuktikan bahwa kepuasan pelanggan menjadi variabel mediasi service quality terhadap kesetiaan pelanggan. Sidharta dan Keni (2015) dalam penelitianya menemukan bahwa physical environment memiliki pengaruh tidak langsung terhadap kesetiaan pelanggan, dan kepuasan pelanggan memediasi pengaruh physical environment ke kesetiaan pelanggan. Berdasarkan paparan diatas, maka hipotesis penelitian adalah sebagai berikut :

$\mathrm{H} 4 \mathrm{a}$ : Terdapat pengaruh positif customer perceived value terhadap kesetiaan pelanggan dengan dimediasi oleh kepuasan pelanggan.

$\mathrm{H} 4 \mathrm{~b}$ : Terdapat pengaruh positif service quality terhadap kesetiaan pelanggan dengan dimediasi oleh kepuasan pelanggan.

$\mathrm{H} 4 \mathrm{c}$ : Terdapat pengaruh positif physical environment terhadap kesetiaan pelanggan dengan dimediasi oleh kepuasan pelanggan.

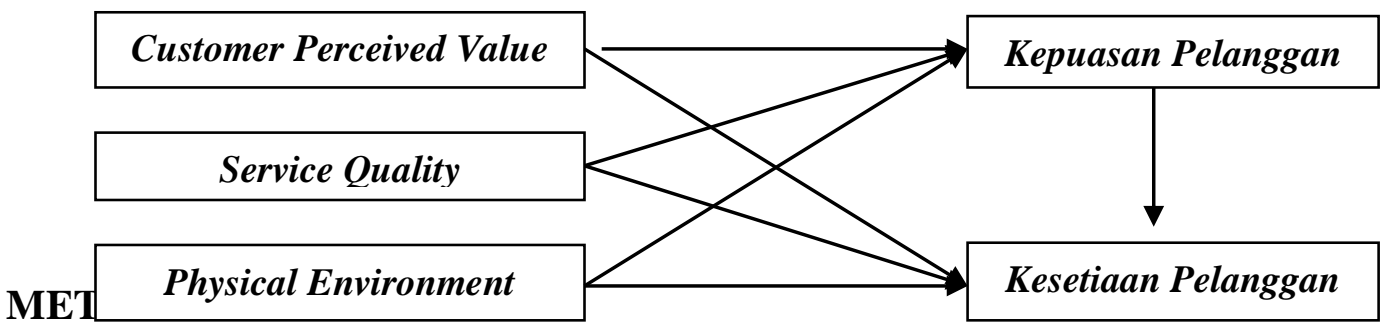

Populasi dan Metode Pengambilan Sampel. Populasi dalam penelitian ini adalah orang yang pernah membeli barang (selain makanan) di salah satu toko furniture di Jakarta . Ukuran sampel yang digunakan dalam penelitian ini adalah 326 orang. Metode pengambilan sampel yang digunakan adalah non-probability sampling. Teknik pengambilan sampel yang digunakan adalah convenience sampling. Berdasarkan data yang terkumpul, mayoritas karakteristik responden pada penelitian ini adalah wanita (71\%), berusian 21-30 tahun (69\%) 
dengan pendidikan terakhir mayoritas adalah S1 (73\%) yang berpenghasilan rata-rata Rp 2.000.000-9.000.000 (59\%).

Variabel dan Pengukuran. Pada penelitian ini, variabel customer perceived value, service quality, physical environment merupakan variabel independent, sedangkan kesetiaan pelanggan adalah variabel dependent dengan kepuasan pelanggan sebagai variabel mediator. Untuk mengukur variabel ini, menggunakan beberapa instrument yang diadaptasi dari studi penelitian terdahulu, Skala pengukuran yang digunakan adalah Skala Likert 5 poin dengan 1 menunjukan "sangat tidak setuju" dan 5 menunjukan "sangat setuju". Dari hasil uji validitas dan reliabilitas menunjukan bahwa semua variabel yang digunakan dalam penelitian ini adalah valid dan reliabel.

Tabel ini dibawah ini menunjukan pengukuran masing - masing variabel dan sumbernya :

Tabel 1. Variabel dan Pengukuran

\begin{tabular}{l|c|l}
\hline \multicolumn{1}{c|}{ Variabel } & Jumlah Item & \multicolumn{1}{|c}{ Sumber } \\
\hline Variabel Independent & & \\
1. Customer Perceived Value & 4 & Yang \& Peterson (2004) \\
2. Service Quality, terdiri dari & & \\
Tangible & 4 & Parasuraman, Berry \& \\
Realibility & 5 & Zeithaml (1988) \\
Responsiveness & 4 & \\
Assurance & 3 & \\
Emphaty & 5 & \\
\hline
\end{tabular}

\begin{tabular}{l|c|l}
\hline \multicolumn{1}{c|}{ Variabel } & Jumlah Item & \multicolumn{1}{c}{ Sumber } \\
\hline $\begin{array}{l}\text { Variabel Independent } \\
\text { 3. Physical Environment, terdiri }\end{array}$ & & \\
$\quad$ dari & 5 & \\
$\quad \begin{array}{l}\text { Facility Aesthetics } \\
\text { Ambience }\end{array}$ & 4 & \\
$\quad$ Lighting & 2 & Ryu dan Jang (2008) \\
$\quad \begin{array}{l}\text { Table Setting } \\
\text { Layout }\end{array}$ & 2 & \\
$\quad$ Service Staff & 3 & Ryu et.al (2008), Zeithaml \\
et.al (1996), Cheng et.al \\
$\quad$ Kepuasan Pelanggan & 2 & (2008) \\
\hline Variabel Dependent & 4 & Hasan et.al (2013) \\
Kesetiaan Pelanggan & & \\
\hline
\end{tabular}

Metode Analisis Data. Metode analisis data yang digunakan adalah analisis regresi ganda dan sederhana. Sedangkan, untuk uji asumsi seperti uji normalitas, uji multikolinieritas dan uji heteroskedastisitas telah dilakukan sebelumnya dan hasilnya menunjukan semua uji asumsi sudah terpenuhi. Untuk analisis mediasi dalam penelitian ini menggunakan tiga analisis regresi menurut Baron \& Kenny (1986). Pengujian dalam penelitian ini menggunakan program SPSS. Taraf signifikansi yang digunakan dalam penelitian ini adalah 0,05 .

Pengujian untuk analisis data dilakukan dengan pembagian menjadi 4 model yaitu model 1 untuk menguji hipotesis pertama yaitu pengaruh customer perceived value, service quatity, 
dan physical environment terhadap kesetiaan pelanggan, model 2 untuk menguji hipotesis kedua yaitu untuk pengaruh customer perceived value, service quality, dan physical environment terhadap kepuasan pelanggan, model 3 untuk menguji hipotesis ketiga yaitu pengaruh kepuasan pelanggan terhadap kesetiaan pelanggan dan model 4 digunakan untuk menguji hipotesis keempat yaitu untuk menguji peran kepuasan pelanggan dalam memediasi pengaruh customer perceived value, service quality, dan physical environment terhadap kesetiaan pelanggan.

ANALISA DAN PEMBAHASAN

Tabel 2. Hasil Pengujian Hipotesis

\begin{tabular}{|c|c|c|c|c|}
\hline & Hipotesis & B & Sig & Kesimpulan \\
\hline H1a & $\begin{array}{l}\text { Terdapat pengaruh positif } \begin{array}{r}\text { antara } \\
\text { customer perceived value } \\
\text { kesetiaan pelanggan. }\end{array} \\
\text { terhadap }\end{array}$ & 0,229 & 0,000 & Tidak Ditolak \\
\hline $\mathrm{H} 1 \mathrm{~b}$ & $\begin{array}{l}\text { Terdapat pengaruh positif antara service } \\
\text { quality terhadap kesetiaan pelanggan. }\end{array}$ & 0,565 & 0,000 & Tidak Ditolak \\
\hline $\mathrm{H} 1 \mathrm{c}$ & $\begin{array}{l}\text { Terdapat pengaruh positif antara } \\
\text { physical environment terhadap kesetiaan } \\
\text { pelanggan. }\end{array}$ & 0,304 & 0,000 & Tidak Ditolak \\
\hline $\mathrm{H} 2 \mathrm{a}$ & $\begin{array}{l}\text { Terdapat pengaruh positif antara } \\
\text { customer perceived value terhadap } \\
\text { kepuasan pelanggan. }\end{array}$ & 0,181 & 0,000 & Tidak Ditolak \\
\hline $\mathrm{H} 2 \mathrm{~b}$ & $\begin{array}{l}\text { Terdapat pengaruh positif antara service } \\
\text { quality terhadap kepuasan pelanggan. }\end{array}$ & 0,531 & 0,000 & Tidak Ditolak \\
\hline $\mathrm{H} 2 \mathrm{c}$ & $\begin{array}{l}\text { Terdapat pengaruh positif antara } \\
\text { physical environment terhadap kepuasan } \\
\text { pelanggan. }\end{array}$ & 0,375 & 0,000 & Tidak Ditolak \\
\hline $\mathrm{H} 3$ & $\begin{array}{l}\text { Terdapat pengaruh positif antara } \\
\text { pelanggan terhadap kesetiaan pelanggan. }\end{array}$ & 0,821 & 0,000 & Tidak Ditolak \\
\hline & Hipotesis & & $t$ & Hasil \\
\hline $\mathrm{H} 4 \mathrm{a}$ & \multicolumn{2}{|c|}{$\begin{array}{l}\text { Kepuasan pelanggan memediasi pengaruh customer } \\
\text { perceived valuesecara positif terhadap kesetiaan } \\
\text { pelanggan }\end{array}$} & 10,54 & Tidak Ditolak \\
\hline $\mathrm{H} 4 \mathrm{~b}$ & \multicolumn{2}{|c|}{$\begin{array}{l}\text { Kepuasan pelanggan memediasi pengaruh service } \\
\text { quality secara positif terhadap kesetiaan pelanggan }\end{array}$} & 8,72 & Tidak Ditolak \\
\hline $\mathrm{H} 4 \mathrm{c}$ & \multicolumn{2}{|c|}{$\begin{array}{l}\text { Kepuasan pelanggan memediasi pengaruh physical } \\
\text { environment secara positif terhadap kesetiaan } \\
\text { pelanggan }\end{array}$} & 10,51 & Tidak Ditolak \\
\hline
\end{tabular}

Berdasarkan hasil pengujian hipotesis pada model 1, maka dapat disimpulkan bahwa customer perceived value, service quality, dan physical environment berpengaruh positif terhadap kesetiaan pelanggan . Hipotesis H1a dan H1b ini sesuai dengan penelitian Rasheed dan Abadi (2014) yang menyatakan bahwa customer perceived value dan service quality adalah faktor yang berpengaruh positif terhadap kesetiaan pelanggan. Memberikan customer perceived value dan kualitas pelayanan yang baik akan membuat pelanggan merasa diperlakukan dengan baik sehingga akan loyal. Kemudian untuk hipotesis H1c juga sudah sesuai dengan Sidharta dan Keni (2015) yang mengatakan adanya pengaruh positif dari physical environment terhadap kesetiaan pelanggan. Dengan memberikan kondisi fisik lingkungan yang baik, akane meningkatkan kenyamanan pelanggan ketika berada di tempat tersebut sehingga akhirnya akan mempengaruhi kesetiaan pelanggan. 
Hipotesis kedua ( model 2) digunakan untuk menguji apakah customer perceived value, service quality, dan physical environment berpengaruh positif terhadap kepuasan pelanggan .Berdasarkan hasil rekapitulasi hipotesis diatas juga diketahui bahwa hipotesis kedua terbukti bahwa customer perceived value, service quality, dan physical environment berpengaruh positif terhadap kepuasan pelanggan. Hipotesis $\mathrm{H} 2 \mathrm{a}$ dan $\mathrm{H} 2 \mathrm{~b}$ sudah sesuai dengan penelitian McDougall dan Levesque (2000) yang menemukan bahwa perceived value dan service quality berpengaruh positif terhadap kepuasan konsumen. Ketika pelanggan diberikan suatu nilai yang lebih tinggi dari ekspektasi mereka dengan ditambah kualitas layanan yang maksimal, akan mendorong kepuasan pelanggan. Lebih lanjut untuk H2c, sudah sejalan dengan Chang (2009), yang menyatakan bahwa physical environment memiliki efek yang signifikan terhadap kepuasan pelanggan.Pengusaha perlu meyakini bahwa dengan kondisi lingkungan fisik toko yang baik akan menunjang persaan senang pelanggan sehingga akan timbul kepuasan pelanggan.

Hipotesis ketiga (H3) adalah untuk menguji apakah kepuasan pelanggan berpengaruh positif terhadap kesetiaan pelanggan. Hasil pengujian hipotesis pada tabel 2 menunjukan pada penelitian ini menemukan bahwa kepuasan pelanggan berpengaruh signifikan pada kesetiaan pelanggan. Hasil ini sejalan dengan penelitian Yang dan Peterson (2004) percaya bahwa kepuasan pelanggan akan berpengaruh signifikan terhadap kesetiaan pelanggan. Pelanggan yang merasa puas akan produk dan layanan dari toko tersebut, maka akan mendorong terciptanya kesetiaan pelanggan untuk membeli produk dari toko tersebut.

Hipotesis keempat (H4) menguji apakah kepuasan pelanggan memediasi customer perceived value, service quality, dan physical environment terhadap kesetiaan pelanggan. Hasil pengujian dilakukan dengan menggunakan path analysis menunjukan bahwa pada penelitian ini, kepuasan pelanggan memediasi customer perceived value $(\mathrm{H} 4 \mathrm{a})$, service quality (H4b), dan physical environment $(\mathrm{H} 4 \mathrm{c})$ terhadap kesetiaan pelanggan secara positif. Hasil ini sesuai dengan penelitian Putranto (2015) yang menyatakan bahwa perceived value berpengaruh terhadap kesetiaan konsumen dengan dimediasi kepuasan. Pertama, dengan memberikan value kepada pelanggan sebaik mungkin, akan memberikan kesan positif. Pelanggan akan puas dan kemudian akan mendorong untuk setia pada toko tersebut. Kemudian untuk service quality (H4b), juga sesuai dengan Kaura,et.al (2015) yang menemukan bahwa kepuasan pelanggan menjadi variabel mediasi service quality terhadap kesetiaan pelanggan. Apabila toko memberikan kualitas pelayanan yang baik maka pelanggan akan merasa puas dan kemudian pelanggan untuk datang kembali di masa mendatang. Dan yang terakhir, hasil H4c sudah sesuai dengan penelitian Ryu dan Han (2010) dalam penelitianya menemukan bahwa kepuasan pelanggan memediasi pengaruh physical environment ke kesetiaan pelanggan. Lingkungan fisik yang baik dan nyaman akan menciptakan perasaan positif yang membangun kepuasan pelanggan dan mendorong terciptanya kesetiaan pelanggan.

Berdasarkan hasil diatas, maka seluruh hipotesis penelitian ini terbukti dengan adanya data secara empiris. Kesetiaan pelanggan dapat diprediksi oleh customer perceived value, service quality, dan physical environment serta dapat dimediasi oleh kepuasan pelanggan. Dengan demikian, maka dapat dilihat bahwa kesetiaan pelanggan dapat dipengaruhi oleh persepsi nilai yang dirasakan konsumen, kualitas layanan, dan kondisi fisik lingkungan di toko furniture tersebut .

\section{PENUTUP}

Kesimpulan. Dalam melakukan bisnis apapun, pelaku bisnis mengharapkan bisnis tersebut dapat bertahan lama. Salah satu faktor penting dalam mewujudkannya adalah menjaga pelanggan agar loyal untuk melakukan pembelian terus menerus. Tidak hanya mengandalkan kekuatan brand dan inovasi, tetapi perlu ada faktor lain. Perceived value, 
service quality, dan physical environment juga menjadi hal yang signifikan yang dapat berpengaruh terhadap keberlangsungan bisnis.

Dalam penelitian ini menemukan bahwa customer perceived value, service quality dan physical environment memiliki pengaruh kuat terhadap kepuasan dan kesetiaan pelangan di sebuah toko furniture di Jakarta. Apabila pelanggan memperoleh persepsi nilai yang lebih tinggi dari apa yang diharapkan, maka akan menimbulkan kepuasan pelanggan yang kemudian akan mendorong kesetiaan pelanggan makin tinggi. Demikian juga, apabila toko tersebut dapat memberikan kualitas servis/pelayanan yang semakin baik, maka akan membuat pelanggan merasa dihargai sehingga pelanggan akan puas dan secara kontinu membeli terus-menerus. Dan terakhir, tidak kalah penting adalah, toko tersebut wajib memperhatikan kualitas lingkusan fisik nya, agar dapat memberikan kenyamanan dan kesenangan bagi pelanggan yang datang sehingga menciptkan kepuasan pelanggan dan akhirnya akan terus berkeinginan untuk kembali datang dan membeli barang di toko tersebut.

Saran. Peneliti menyarankan agar toko tersebut harus memperhatikan faktor customer perceived value, service quality, dan physical environment dalam kegiatan operasional nya. Perceived value dapat ditingkatkan dengan terus memberikan inovasi produk yang menarik dengan harga yang wajar. Service quality dapat ditingkatkan dengan meningkatkan komitmen toko dan pegawai untuk membantu pelanggan. Terakhir, physical environment juga dapat ditingkatkan dengan menjaga kebersihakn lingkungan toko. Hal itu dikarenakan ketiga faktor tersebut sudah teridentifikasi berpotensi menciptakan keputusan pelanggan yang akan meningkatkan kesetiaan pelanggan. Bagi penelitian selanjutnya, peneliti menyarankan agar memperluas jangkauan pengambilan sample dan menambah variabel lain. Hal tersebut agar memperkuat dan melengkapi penelitian sebelumnya.

\section{DAFTAR PUSTAKA}

Baron, R. M., \& Kenny, D. A. (1986). The Moderator-Mediator Variable Distinction In SocialPsychological Research: Conceptual, Strategic, And Statistical Considerations. Journal of Personality and Social Psychology, 51,pp. 1173-1182.

Chang Phd, Kyungro.,(2009). " The Impact of Perceived Physical Environments on Customers Satisfaction and Return Intentions". Journal of Professional Services Marketing, Vol.21 (02)

Cheng.T.C.E, Lai L.C.F., \& Yeung A.C.L.(2008) " The Driving Forces of Customer Loyalty: A Study of Internet Service Provider in Hongkong," International Journal of EBusiness Research, 4(4),26-42.

Griffin, Jill. (2003). Customer loyalty. Jakarta: Erlangga

Hassan,M., Hassan,S., Nawaz,M.S., \&Aksel,I. (2013). "Measuring Customer Satisfaction and Loyalty through Service Fairness, Service Quality, and Price Fairness Perception: An Empirical Study of Pakistan Mobile Telecommunication Sector," Science International,25(4),971-980

Kandampully, Jay.,\&Suhartanto, Dwi. (2000). "Customer Loyalty In The Hotel Industry : The Role Of Customer Satisfaction And Image" . International Journal of Contemporary Hospitality Management, Vol.12 (06), pp.346-351

Kaura, Vinita., Prasad, Ch.S.Durga., \& Sharma, Sourabh. (2015). "Service Quality, Service Convenience, Price and Fairness, Customer Loyalty, and mediating role of Customer Satisfication"International Journal of Bank Marketing, Vol. 33(04), pp.404-422

Kotler,Philip dan Keller,K.L. (2012). Marketing Management. 14 Edition. Harlow : Pearson Education Limited 
Kotler,P., \& Keller,.L. (2015). Marketing Management $15^{\text {th }}$ edition. NewJersey : Pretince Hall.

Mc.Dougall, Gordon H.G., \& Levesque, Terrence. (2000). "Customer Satisfaction With Services : Putting Perceived Value Into The Equation" Journal of Services Marketing, Vol. 14 (05), pp.392-410

Nguyen,N., \& Leblanc,G. (2002). " Contact Personel, Physical Environment and The Perceived Corporate Image of Intangible Services by New Clients," International Journal of Service Industry Management 13(3),242-262.

Putranto, Satrio (2015). "Pengaruh Perceived Value terhadap Loyalitas Konsumen dengan Kepuasan sebagai Variabel Mediasi“ Jurnal Fakultas Ekonomi Manajemen

Rasheed, F.A., \& Abadi,M.F. (2014). "Impact of Service Quality, Trust, and Perceived Value on Customer Loyalty in Malaysia Service Industries," Social and Behavioral Sciences, 164,298-304

Ryu, K., \& Jang, S. (2008). DINESCAPE: A scale for customers' perception of dining environments. Journal of Foodservice Business Research, 11(1), 2-22.

Ryu, K., \& Han, H. (2010). "Influence of Physical Environment on Disconfirmation, Customer Satisfaction, and Customer Loyalty for First-time and Repeat Customers in Upscale Restaurants," International CHRIE Conference-Refereed Track, 13-21.

Sidharta, Eveline Larisa\& Keni (2015). “ Pengaruh Service Fairness, Empathy dan Physical Environment terhadap Customer Satisfaction dan Customer Loyalty,"Jurnal Manajemen Vol.XIX, No.02 Juni 2015 : 263-279

Tjiptono, Fandy. (2005). Strategi Pemasaran, Yogyakarta: Penerbit Andi,

Tsiros,Michael., Mittal,Vikas., \& Ross, William T. (2004). “ The Role of Attributions in Customer Satisfaction : A Reexamination" Journal of Consumer Research Vol.31 (02), 476

Yang,Z.,\&Peterson,R.T. (2004). "Customer Perceived Value, Satisfaction, and Loyalty: The Role of Switching Costs," Psychology \& Marketing,Vol.21 (10), 799-822

Zeithaml,V.A., Berry, L.L., \& Parasuraman , A (1988). "Consumer Perception of Price, Quality, and Value : A Means- End Model and Synthetsis of Evidence," Journal of Marketing, 52,2-22

Zeithaml,V.A., Berry, L.L., \& Parasuraman, A (1996). "The Behavioral Consequance of Service Quality," Journal of Marketing, 60(4), 31-46 


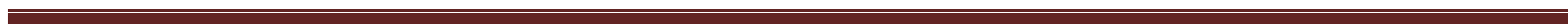
$\cdot$ 